\title{
Only as Special as Necessary: Adapted Books in a Universal Design Perspective
}

\author{
Gerd BERGET ${ }^{\mathrm{a}, 1}$

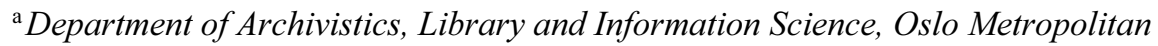 \\ University, Norway
}

\begin{abstract}
Providing access to high quality books for all types of readers is a premise for cultural democracy. Many people, however, have challenges reading mainstream books. There might be diverse reasons why people find reading challenging. Some examples are reading impairments, reduced vision, cognitive impairments, learning a new language, or due to stress, fatigue or illness. To ensure everyone access to literature, it is therefore vital to produce books that can (and will) be read by a wide range of users. This case study addresses the following research questions: Do adapted books represent accessible or universal design? Can adapted books be perceived as motivating to read for all types of readers? Are "special books" necessary to ensure that all users have access to high quality literature? In Norway, the association Books for Everyone develops adapted, printed fictional books to accommodate various types of reading challenges. This paper examines the production of these books and uses this collection to investigate the research questions. The main finding is that most of the books by Books for Everyone can be considered examples of universal design, rather than "special books" directed at a very narrow user group. Moreover, there seems to be a limited need for "special books", except for books targeting readers with severe cognitive or sensory impairments. By applying the universal design approach, fictional literature can potentially make books more accessible for all types of readers.
\end{abstract}

Keywords. Adapted literature, Books for everyone, reading challenges, cultural democracy, universal design

\section{Introduction}

Fictional books represent an important part of our culture. Reading books may have many benefits, such as supporting the development of language and reading skills [1,2], improving social skills and increasing empathy [3]. For various reasons, however, "mainstream literature" is not always accessible for all types of readers, and certain adaptations might be necessary for some cohorts. For instance, people with reduced vision might require large letters or books printed in Braille, while people who are deaf may prefer video books with sign language. Books in Braille or sign language are typically tailored for a limited user group, e.g. people who can read Braille or speak sign language and might therefore be regarded as accessible design. Other types of adapted books may apply easy language, have a modified content or a frequent use of illustrations targeted at people with reading impairments or intellectual impairments. Some of these

${ }^{1}$ Corresponding Author, Gerd Berget, Department of Archivistics, Library and Information Science, Oslo Metropolitan University, Postboks 4 St. Olavs plass, N-0130 OSLO, Norway; E-mail: gerd.berget@oslomet.no. 
books might be suitable for many types of readers, e.g. non-native speakers learning a new language, people who are ill or simply too tired to engage in reading more demanding books. Consequently, such books may be regarded as examples of universal design. Nevertheless, to reach the potential readers, these books must be regarded as relevant or interesting for more than a narrow target group to reach its potential.

The overall purpose of this paper is to investigate whether it is possible to produce high quality books that are perceived as interesting and relevant for a broad diversity of readers, while at the same time avoid "special books" directed at limited target groups. The paper is based upon the following research questions:

$R Q_{1}$ : Do adapted books represent accessible or universal design?

$R Q_{2}$ : Can adapted books be perceived as motivating to read for all types of readers?

$R Q_{3}:$ Are "special books" necessary to ensure that all users have access to high quality literature?

In Norway, the association Books for Everyone develops books adapted for a variety of reading challenges. In this paper, the complete book production by Books for Everyone is used as a case study. To answer $\mathrm{RQ}_{2}$, the model for the process of choosing books for pleasure-reading by Ross [4] will be applied as a theoretical framework.

The paper is structured as follows: First, the background addresses the importance of reading, the concepts 'adapted books', reading challenges and universal design. The methodology chapter introduces the association Books for Everyone, which is applied as a case study in this paper. Then follows the theoretical framework applied in this study, namely Ross' model for the process of selecting books for pleasure-reading [4]. Finally, there is a short discussion of the research questions and a conclusion.

\section{Background}

\subsection{The Importance of Reading "the Right Books"}

There are various positive effects of leisure reading, such as improved reading speed, reading comprehension and summarization skills $[1,5]$. Reading has also been reported to increase empathy and understanding of the subjective state of others through fictional characters with various identities and personal values [6]. Consequently, it is important that all people have equal access to books, to support well developed literacy skills and personal development. Ensuring everyone access to books is also vital to achieve cultural democracy.

There are several reasons why people read books, such as gaining new knowledge or for leisure. Becker, McElvany and Kortenbruck [1] addressed reading in relation to intrinsic and extrinsic motivation. They found that intrinsic motivation was a key predictor for literacy. Stephen Krashen applies the term "free voluntary reading" and defines this activity as "reading because you want to" [7]. This type of reading is regarded as vital for increasing literacy. According to Krashen [7], an important aspect of free voluntary reading is being able to put down a book you don't like and choose another instead. Selecting "the right book", however, is a skill and seems to be part of a self-reinforcing system. According to Ross [4], bad reading experiences may threaten the pleasure in reading in general. Making disappointing choices reduces the general desire to read, while successful choices will sustain the pleasure of reading. Similar findings have been reported by Swartz and Hendricks [8]. 
According to Gambrell [2] people with reading challenges tend to select books too advanced for their reading skills because they do not want to be seen reading "the easy books". Gambrell [2] suggests avoiding labelling books as "easy", since such labels will negatively affect the choice of books. This finding is consistent with Berget and Fagernes [9], who reported that adults with dyslexia "felt stupid" if they were given books that were clearly modified for a smaller cohort and not targeted at the general population. Consequently, there is a need to consider how to develop and promote books that will ensure everyone access to age-appropriate and accessible literature, while at the same time not interfere with the intrinsic motivation to read. Removing the division between adapted books and mainstream books may be one measure to increase the motivation to read.

\subsection{Adapted Books}

The term 'adapted book' can refer to several different approaches to book development. Some common examples are transforming novels or graphic novels into movies [10] or modifying books for adults into children's books [11]. Adaptation can also refer to adjusting books for people with disabilities, such as Braille books containing tactile pictures [12] or multimodal books with sign language [13]. Consequently, the adaptation results in two versions of each book, namely the original and a new, modified version. This approach can be related to the concept accessibility. In contrast, 'adapted book' can also refer to the process of developing books where modifications have been incorporated from the beginning and throughout the production of the original book [14]. Consequently, this approach results in one version of the book rather than one mainstream version and one adapted edition, which is in accordance with the universal design paradigm. This approach is consistent with the terminology used by the association Books for Everyone and will be applied in this paper when referring to adapted books.

\subsection{What is a Reading Challenge?}

There are many reasons why people may find mainstream books too demanding to read, and thus require some level of adaptation. Reading challenges, however, have typically been related to reading impairments, such as dyslexia [15], developmental language disorder [16], various forms for developmental or intellectual disabilities [17] or people with hearing impairments [18]. Diagnostic terms such as "reading disorder" or "reading disability" have frequently been applied when referring to these types of reading challenges. In this context, a typical approach has been to make "special books" based on assumed user needs.

Reading challenges, however, are not always related to disabilities, they may also be contextual or situational. For example, reading challenges may be experienced by non-native language speakers [19], people who experience physical or mental illness [20], people who are stressed or tired [21]. Consequently, many types of readers may experience similar challenges as people with reading disabilities and might therefore benefit from reading the same books. In some contexts, it might therefore be more purposeful to apply the term "reading challenges" over "reading disabilities". Moreover, it has been argued that it might be more purposeful to apply the universal design paradigm than the accessibility mode of thought in the development and production of adapted books [14]. 


\subsection{Accessible versus Universal Design}

The difference between accessible and universal design has been broadly discussed in the research literature. Iwarsson and Ståhl [22] emphasize the many aspects of accessibility. While most attention has been directed towards the physical environment, there has been less focus on information and societal activities and services.

According to Iwarsson and Ståhl [22], the starting point for accessibility is dividing the population into two categories based on functional level: "the normal population and the population diverging from normality". Accessible design addresses the latter population, and can be defined as "design that meets prescribed code requirements for use by people with disabilities" [23]. In contrast, universal design is based on the notion that there is one population, comprising of people with various abilities and characteristics, and that user diversity is the norm. Universal design was originally defined by Ronald Mace as "the design of products and environments to be usable by all people, to the greatest extent possible, without the need for adaptation or specialized design" [24].

Accessible design is often added on after or at the end of a design process. In contrast, universal design has been integrated from the start, and is therefore typically less noticeable [23]. Moreover, universal design comprises a broader variety of user characteristics, often referred to as "all people" [24], "a diverse population" [25], "human diversity" [26] or "anyone, including future generations, regardless of age, gender, capacities, or cultural background" [27]. Consequently, universal design covers a broader aspect of user diversity than disabilities, e.g. differences in cultural background, age, gender, and physical or mental condition.

\section{Methods}

This is a case study of the book collection developed by the association Books for Everyone. A theoretical framework was also applied to answer the research question related to motivation $\left(\mathrm{RQ}_{2}\right)$, namely a model on how people choose books for pleasure reading developed by Ross [4]. Both the association Books for Everyone and the model by Ross [4] will be presented in this section.

\subsection{Books for Everyone}

Books for Everyone was established in 2002 and is the main stakeholder developing adapted fictional books in Norway. In this context, adapted does not entail modifying existing books, but rather developing entirely new books. The association is funded through the central government budget in Norway. According to Books for Everyone, they are "working to give everyone access to good books", and the overall goal is "real cultural democracy" [28]. The books developed by Books for Everyone are published on mainstream publishing houses with financial support from the association and look like all other books. A small icon on the cover (see Figure 1) is the only visual cue that a book is developed or supported by Books for Everyone. 


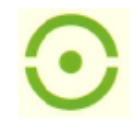

Figure 1. Books for Everyone logo from the back of a book cover.

The motto and starting point for Books for Everyone is: "there is nothing wrong with people who struggle with reading, they just haven't found the right books" [28]. To accommodate the various types of reading challenges, Books for Everyone originally classified the collection into six categories (see Table 1). The categories refer to types of adaptation rather than target group(s). Consultants from Books for Everyone work closely with authors, illustrators and publishers to ensure that the books are accessible for the intended readers of each category. When included in library collections, the books are often labelled with stickers in different colours, to clearly display which category the books belong to.

Table 1: Categories applied by Books for Everyone.

\begin{tabular}{l}
\hline Category \\
\hline Easy to Read \\
Easy to Understand \\
Big Letters \\
Sign Language / Sign Support \\
Alternative Communication Signs \\
Braille / Tactile Pictures \\
\hline
\end{tabular}

Recently, another category "New in Norway" was added. This category is not included in the study because no books have been classified with just this category. It overlaps with other categories, primarily "Easy to Read". It should be noted that the Norwegian name of the category "Easy to Read" translates directly into "A Little Bit to Read", thus avoiding the word "easy". The category "Easy to Understand" translates into "Understandable Content". Table 1 contains the official English translations applied by Books for Everyone today. These translations, however, are under revision, to avoid potentially stigmatizing labels.

Books for Everyone considers several components when developing and producing books, such as the use of font types and font sizes, paper quality, layout and typography. In addition, each of the categories have certain characteristics. Some modifications only affect the presentation of the text, such as the "Big Letters" category, where font size is the only adaptation. For other categories, the content is presented in different languages or writing systems, such as sign language, sign support, alternative communication signs, Braille or tactile pictures.

Other categories are more comprehensive in their adaptations. The "Easy to Read" books apply short sentences and few long or foreign words. Moreover, metaphors are typically not applied, and the relationship between text and illustrations is carefully considered. The "Easy to Understand" books have similar modifications but are typically even more adapted. The stories often contain few characters and settings. These books usually have less text than the "Easy to Read" books and a more limited vocabulary. 


\subsection{Theoretical Framework}

The theoretical framework applied in this paper is the comprehensive model for the process of selecting books for pleasure reading developed by Ross [4]. The model is based on interviews with 194 committed readers. According to Ross [4], people who read frequently have better skills in selecting books than reluctant readers due to a broader familiarity with books. Finding books that provide positive reading experiences is closely related to the development of literacy because it motivates the reader to choose reading over other activities. Moreover, learning how to choose a book is an important skill, since disappointing choices may kill the desire to read. According to Ross [4], "each unsuccessful choice decreases the beginning reader's desire to read, which in turn reduces the likelihood of further learning based on interaction with books".

Ross [4] suggests a model consisting of five main categories that jointly affect the process of selecting a book for pleasure reading. These categories are: 1) reading experience wanted, 2) alerting sources, 3) elements of a book, 4) clues on the book and 5) economic and intellectual effort required. For each of these categories, Ross [4] lists several subcategories. The list is too comprehensive to include all the motivational factors in this study. Table 2 contains the subcategories regarded as most relevant to answer $\mathrm{RQ}_{2}$. Some categories were chosen because they were the most important strategies reported (e.g. author, genre, cover and mood) or they may be regarded as especially important in context of reading challenges (e.g. easy vs. challenging text and physical size of the book). Reading challenges is here applied in the broadest sense, as situational and contextual, and potentially experienced by all readers at certain times.

Table 2. Selected criteria for the process of choosing a book for pleasure reading [4].

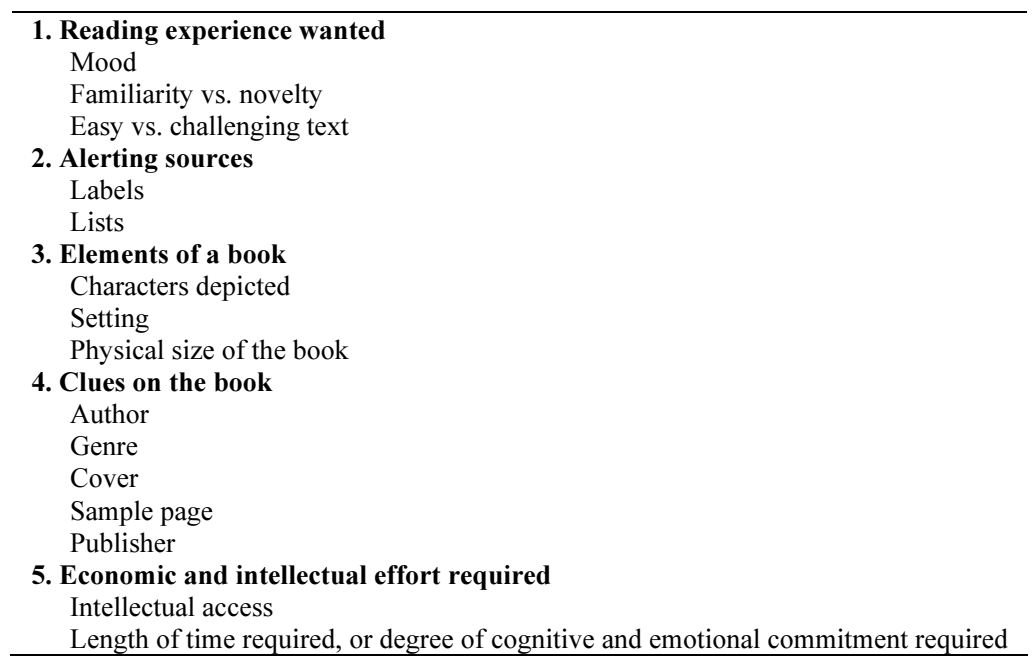

Ross emphasizes the personal context when a reader engages in a book, which includes literary competence, preferences developed during previous reading, events taking place at the time of selecting a book in addition to mood and time available for reading. For instance, people who are under stress, tired or busy will typically select easy reads, short books or old favourites [4]. Moreover, people try to balance safety and certainty of success with novelty and surprise. Finally, Ross [4] emphasizes that the opportunity to choose books for pleasure-reading has value in itself. 


\section{Findings}

The purpose of this study was twofold; First, to explore whether adapted books represent accessible or universal design $\left(\mathrm{RQ}_{1}\right)$. Second, to investigate whether it is possible to produce books that are relevant and accessible for all types of readers, without special considerations $\left(\mathrm{RQ}_{2}\right.$ and $\left.\mathrm{RQ}_{3}\right)$. This section presents the findings and an overall discussion of the research questions.

\subsection{The Book Collection - Accessible or Universal design?}

Books for Everyone develops approximately 12-15 books annually, with an overall production of 232 printed books since the establishment in 2002. Table 3 shows the distribution of books according to category, while Figure 2 displays the production over time according to year and category.

Table 3. Book production according to category $(\mathrm{N}=232)$.

\begin{tabular}{lrr}
\hline Category & Books & Percentage \\
\hline Easy to Read & 176 & $75.9 \%$ \\
Easy to Understand & 33 & $14.2 \%$ \\
Braille / Tactile Pictures & 10 & $4.3 \%$ \\
Big Letters & 6 & $2.6 \%$ \\
Sign Language / Sign Support & 4 & $1.7 \%$ \\
Alternative Communication Signs & 3 & $1.3 \%$ \\
\hline
\end{tabular}

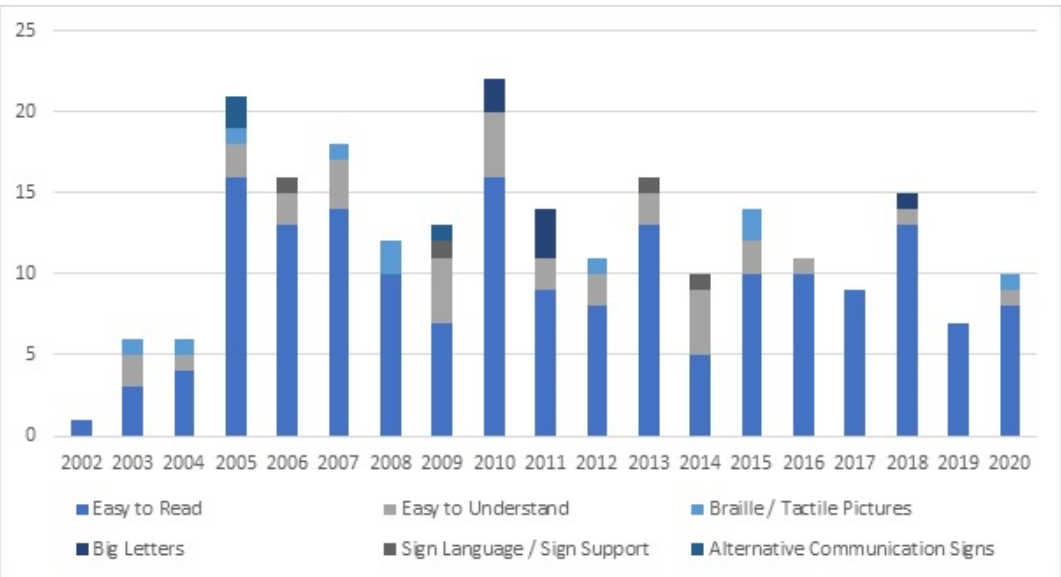

Figure 2. Books published by Books for Everyone according to year and category (N=232).

One cannot assume that everyone read books similarly. Some people read printed text, others apply Braille and tactile pictures while some rely on pictograms such as Bliss. In terms of accessible versus universal design, language and writing system might be the characteristics most closely related to impairments and accessibility. For example, a book printed in Braille letters will typically represent an adaptation that is only targeted at people with severely reduced vision who can read Braille. Consequently, such books might have a very narrow target group. The same reasoning applies to sign language and alternative communication signs. 
Only a small portion of the books developed by Books for Everyone are adapted using alternative languages and writing systems targeting small user groups. In total, $7.3 \%(n=17)$ of the books are written with Braille/Tactile pictures, sign language/sign support or alternative communication signs. Most of these books, however, include printed text as a second modality, and can therefore potentially be read by different types of people. Nevertheless, it is probably not likely that readers beyond the target group would select these books, e.g. a sighted person reading a Braille book. Consequently, most of these books should probably be regarded as accessible design. The same reasoning may also be applied to the books printed in big letters $(2.6 \%$ of the books, $\mathrm{n}=6$ ). Although they in theory may be read by everyone, it is less likely that most users would prefer this format.

There are, however, examples of books where Braille and tactile pictures can appeal to all types of readers, namely children's books. Books with strong colours and tactile pictures (see Figure 3) may be equally interesting for children with and without visual impairments. When presenting the text in printed alphabet and Braille, the target group is broader, and the book becomes an example of best practice of universal design rather than accessible design. Consequently, when using language or writing system as criterion, some of the books can still be defined as universal design.

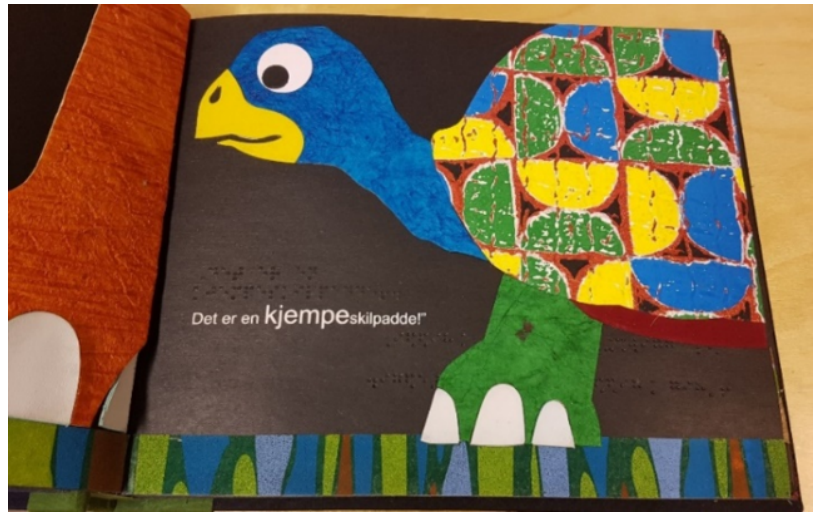

Figure 3. Excerpt from “Do you know the giant?" [29]. C Fortellerforlaget. Printed with permission.

"Easy to Understand" comprises 14.2\% ( $\mathrm{n}=33$ books) of the collection. Most of these books are adapted in terms of easy language, a limited set of characters and settings in addition to a broad use of illustrations. The books in this category directed at people with severe intellectual impairments are potentially targeted at a very limited user groups and may be regarded as examples of accessible design. Other books may be more relevant for other users, as well. This category will be discussed more closely in the next section, exploring the motivational factors by [4].

"Easy to Read" is the largest category representing 75.9\% of the collection ( $\mathrm{n}=176$ books). These books are adapted for various types of reading challenges, such as dyslexia, ADHD, illness or second-language learning. These books should in theory be relevant for a broad diversity of users, which fits well with the universal design paradigm. In the next section these books will be discussed more closely in terms of motivational factors. 


\subsection{Adapted Books and Motivational Factors}

Based on the specific adaptations applied to the different categories, the main portion of books developed by Books for Everyone may potentially be regarded as universal design. However, they may not really be perceived as universally designed if the potential readers regard these as "special books" developed for a limited user group. Consequently, one may argue that the books should also comply with several of the highly used criteria for selecting a book for pleasure reading. In this section, the selected factors from the model by Ross [4] will be discussed in relation to the book collection. This section will primarily address the categories "Easy to Read" and "Easy to Understand", with a few exceptions, since these two categories seem best suited for a broader audience.

\subsubsection{Reading Experience Wanted}

Three criteria were selected for the category reading experience wanted: mood, familiarity vs. novelty and easy vs. challenging text.

According to Ross [4], mood is an important and frequently applied criterion. People who are tired, stressed or busy typically select short books or easy reads. The books in the category "Easy to Read" will comply well with this criterion. These books are typically shorter than mainstream books and apply an easier language. Some of the books labeled "Easy to Understand" may also be relevant. Due to the more extensive adaptation, however, fewer of these books may be selected by a diversity of readers.

The second criterion was familiarity vs. novelty. For certain users, familiarity might be particularly important, such as people with dementia. Books for Everyone has produced several picture books, for example "Memories in picture: A picture book for people with dementia" [30]. This book consists primarily of photographs from the old days (see Figure 4) with a purpose to trigger memories to recollect the past. At first sight, such a book would typically apply to a very narrow user group. Nevertheless, these books might be equally interesting in other contexts, for example for elderly people to reminisce about their childhood with their grandchildren. Such books may also be useful at language cafes, for non-native language speakers, people who are illiterate or severely ill.

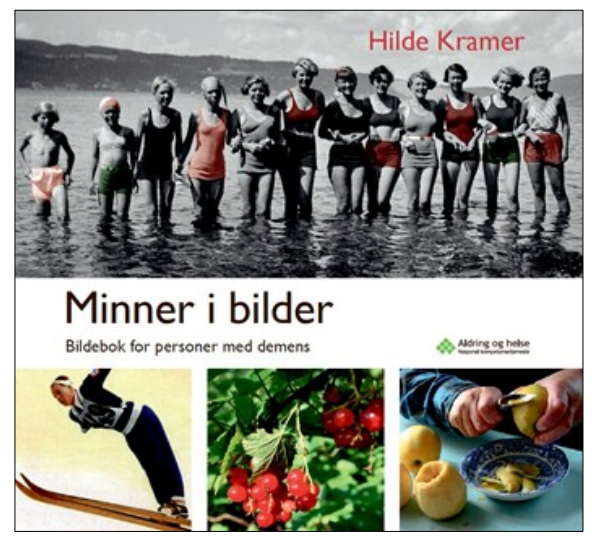

Figure 4. The book cover of "Memories in pictures" [30]. 
Familiarity may also be particularly relevant for users with certain cognitive impairments. One example is the book "Friends: A book for people with developmental impairments and their helpers" [31], which tells the life-story of a person with Down syndrome (see Figure 5). The book covers topics such as co-determination and living in a group home, which are typically not covered in mainstream literature. Such books are examples of accessible design, targeting a more limited user group, since most readers will not be familiar with such topics or perceive them as particularly relevant.

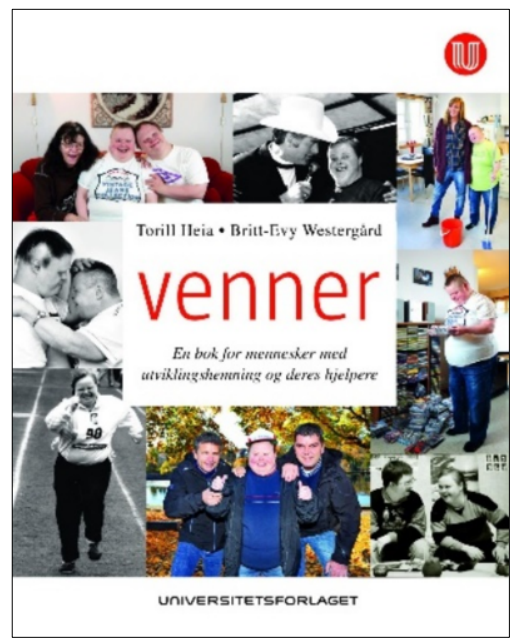

Figure 5. The book cover of "Friends" [31].

A need for familiarity is a potentially difficult criterion. Familiarity may not always be predictable. Moreover, apprehension of what people feel familiar with and want to read about can potentially be affected by prejudice. One example from the "Easy to Read" category is "The girl who wanted to save the books" [32]. The book tells the story of a girl who loves books and reads all the time (see Figure 6). According to Hanna Bovim Bugge, one of the consultants at Books for Everyone, they were skeptical about this story. They questioned whether books targeted at people with reading challenges should evolve around a main character who loves books. However, when they asked for feedback from a 12-year-old girl with dyslexia, she said: "I liked the book. I liked that it was about a girl who loves book. I want to find joy in reading books, too, just like her!". This example shows that it might be difficult to anticipate what other people may prefer in terms of familiarity. Consequently, it seems purposeful to produce books covering a broad variety of topics for readers with diverse interests.

The third criterion was easy vs. challenging text, which may also be difficult to evaluate. A text can be regarded as challenging based on vocabulary and sentence structure, which may potentially be measured by reading level scales. In addition, there are many other characteristics which apply, such as the organization and general structure of the text, a wide use of complicated metaphors, unfamiliar names of characters or storylines, the reader's background and interests [33]. Many of these elements may be more difficult to measure. Previous research has concluded that measures to make text more accessible for people with reading impairments will also improve the text for all types of readers [34]. Consequently, applying reading levels 


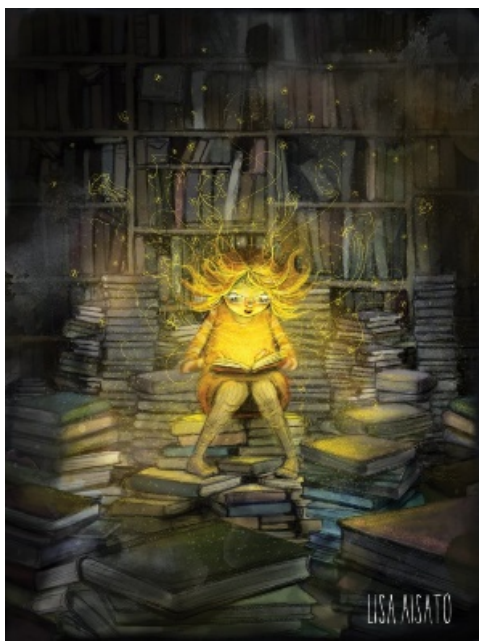

Figure 6. Illustration from Hagerup and Aisato [32]. (C) Lisa Aisato. Printed with permission.

recommended for people with reading impairments will probably make the books easier to read for other types of readers and comply well with this criterion.

\subsubsection{Alerting Sources}

The category alerting sources comprises labels and lists. Regarding labels, there is a small logo printed on the cover of all the books developed by Books for Everyone (see Figure 1). Whether this label will increase or decrease the motivation to select this book probably depends on the familiarity and/or previous experiences reading such books.

The second criterion regards lists, such as prize-winning books or lists of recommended books produced by libraries or other readers. In the later years, several adapted books by Books for Everyone have been nominated to and received acknowledged awards in competition with books on the mainstream market. One example is the graphic novel "Hunger" [35], which has been nominated for and received several prizes e.g. The Brage Prize. It is probable that such awards make more potential readers aware of these books and shows that adapted books can hold high quality while at the same time be accessible for people with reading challenges. It may also increase interest if these books are incorporated in book exhibitions and book talks at the library [14].

\subsubsection{Elements of a Book}

Three criteria were selected from the main category elements of a book: characters depicted, setting and physical size of the book.

The first criterion is characters. The book collection includes a diversity of users, as in any other mainstream book collection. The amount of people with cognitive impairments, however, may be higher in the "Easy to Understand" category. Moreover, each book typically displays fewer characters, to help the reader keep track of the narrative. The same applies to settings. There are many different settings displayed. Each book, however, typically includes less settings than other books, since a limited number of settings is one of the adaptations applied. Both criteria should therefore be possible to apply to the adapted book collection in similar ways as other collections. 
The final criterion is physical size of the book. Books for people with reading challenges should typically not be too long. Nevertheless, there might be many other reasons why people may avoid long books, for instance people who are travelling and do not want to carry a heavy book, if a reader has limited space for reading (e.g. sitting on a crowded train or airplane) or have difficulties holding and lifting heavy books. Consequently, physical size might be relevant for many readers, and should be regarded as a desired feature among many types of readers, not only people with reading impairments.

\subsubsection{Clues on the Book}

Clues on the book comprise author, genre, cover, sample page and publisher. Author is one of the most frequently applied criteria. The authors and illustrators who develop adapted books are typically the same people who produce other mainstream books. Genre is also an important criterion. Books for Everyone develops books in various genres, such as crime, fantasy, romance, science fiction, thrillers and humor books. Different types of literature are also represented, such as novels, short stories, poetry and graphic novels. Consequently, the criteria author and genre should be applicable by all types of readers.

Cover is another criterion applied. According to Ross [4], extensive experience is required to gain the knowledge needed to interpret cover information which may provide valuable clues to the reader. As mentioned, the only visible clue on a book that it is adapted and developed by Books for Everyone is the small logo on the cover (see Figure 1). Some books, however, which clearly address more narrow target groups may have some distinct signals on the cover. One example is the book "Friends" (see Figure 5), where both the title and cover pictures seem to target a particular cohort, namely people with cognitive impairments.

Another criterion is sample page. Several of the books by Books for Everyone have a layout and design that may appear different from many mainstream books, e.g. presenting less dense text or a more extensive use of illustrations. In these cases, it will depend on the preferences of the reader whether the books seem appealing. The final criterion is publisher. The adapted books are published on mainstream publishing houses in Norway. There is no reason to assume that publisher may impact whether the reader selects the adapted book.

\subsubsection{Economic and Intellectual Effort Required}

The criteria selected for the category economic and intellectual effort are intellectual access and length of time required, or degree of cognitive and emotional commitment required.

Intellectual access might be particularly important for people with certain cognitive impairments, which are targeted by the category "Easy to Understand". This is a category that contains a broad variety of books, from picture books to novels and cookbooks. A large portion of these books appear to be tailor-made for certain cohorts, e.g. Down syndrome or dementia. Nevertheless, some of these books might be relevant for other types of readers. One example is picture books for adults (see Figure 7). These books typically contain very little or no text. In the book displayed in Figure 7 [36], the main character tries on new clothes in a fitting room and imagines being another kind of person. The whole sequence is depicted through images only, and the mirror shows the 
character's imagination. Such books can also be relevant for people who are illiterate or in a very early stage of learning a new language, where the vocabulary is rather limited. They might also be purposeful for language cafes, where participants speak different languages. It is important, however, to not provide adults with books that appear childish. Such books may therefore be borderline between universal design and accessibility.

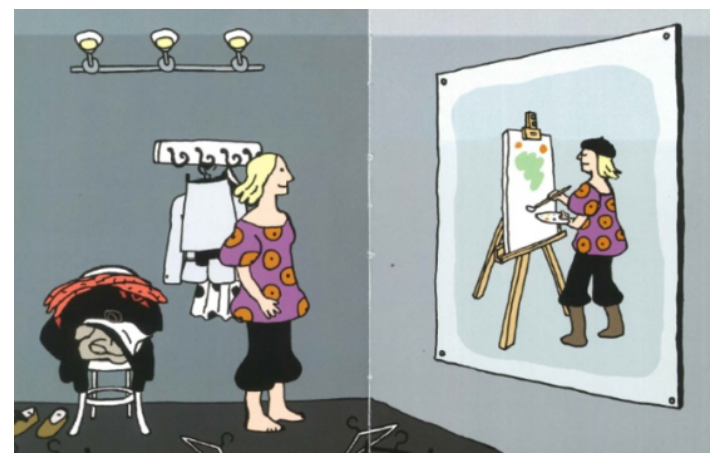

Figure 7. Excerpt from "The New Julie" [36]. Printed with permission from the author and publisher.

The second criterion relates to cognitive and emotional commitment. This is probably one of the key topics related to situational and contextual reading challenges. People who are tired, stressed or ill may prefer less demanding books than they usually read. The same may apply for readers using public transport or are in other busy or noisy environments, affecting the ability to concentrate. In this context, most of the books in the category "Easy to Read" would correspond with the user needs. Although readers may not want something too demanding, they may still want interesting and challenging books. One example that would be potentially appealing in such a situation is "Women in Battle" [37], which has received several prices and been translated into many languages (see Figure 8 for English version).

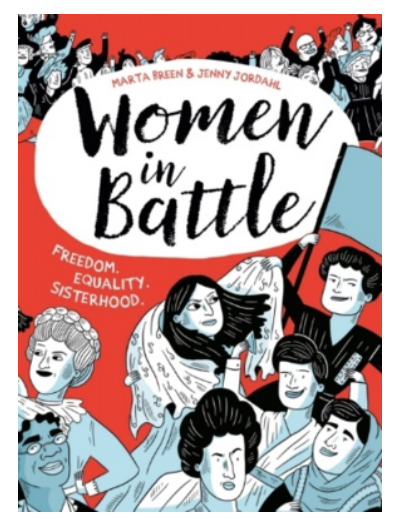

Figure 8. The book cover of "Women in battle" [37]. 


\section{Discussion}

Three research questions were the starting point for this study. Each of these questions will be briefly summarized in this section.

\section{1. $R Q_{1}$ Universal or Accessible Design?}

The first research question $\left(\mathrm{RQ}_{1}\right)$ explored whether the adapted books developed by Books for Everyone represent accessible or universal design $\left(\mathrm{RQ}_{1}\right)$. An analysis of the complete book production suggests that all the books in the "Easy to Read" category can probably be regarded as universal design, since they seem usable for most people [24]. In addition, some of the books in "Easy to Understand" and the children's books in "Braille / Tactile Pictures" can also appeal to a broader audience than the original target group. Consequently, it seems likely that at least $80 \%$ of the books can be defined as universal design. There are also clear examples of accessible design tailored for a narrow user group [22], such as the highly adapted books for people with intellectual impairments or books presented in various languages or writing systems. Consequently, although some adapted books are clearly accessible design, the majority of the collection comply with the universal design mode of thought.

\section{2. $R Q_{2}$ Can Adapted Books be Motivating to Read for all Types of Readers?}

The second research question $\left(\mathrm{RQ}_{2}\right)$ examined a selection of motivational criteria people use when selecting a book for leisure reading [4]. These criteria were discussed in connection with the collection developed by Books for Everyone. The purpose was to investigate whether it is probable that general readers may choose to read an adapted book. Overall, most of the criteria seem to be applicable to this collection. The books represent various genres and book types with different characters and settings. Moreover, they represent good choices for people who for various reasons want less demanding books. Further, they appear similar to other books since they are published at regular, well known publishing houses. Consequently, people will probably not feel stigmatized when reading these books, which is also an important motivational factor $[1,2,9]$. Further, the readers will find familiar authors and illustrators among these books, in which several have received recognized prizes. It is, however, likely that the most adapted books will not suit the criteria, for example due to unfamiliar topics. Consequently, the answer to $\mathrm{RQ}_{2}$ seems to be that a majority of the books should appeal to a diversity of readers. In contrast, the more accessible books might not meet the criteria applied for selecting a book.

\section{3. $R Q_{3}$ Is there a Need for "Special Books"?}

The third research question $\left(\mathrm{RQ}_{3}\right)$ investigated whether "special books" are necessary to ensure all users access to high quality literature. Based on the motivational criteria included in this study, it seems probable that for a diversity of users, universally designed books may be more motivating to read than accessible books. Accessible design typically appeals to a much smaller user group. In some cases, such books might not appeal to the intended user groups either, because people do not want to read the "special books" [2, 9]. Nevertheless, the answer to $\mathrm{RQ}_{3}$ seems to be that in a few cases, there might be a 
need for "special books" to ensure everyone access to literature. Examples are novels in Braille or books adapted for people with severe cognitive impairments. They should, however, not be presented as more special than necessary.

\section{Conclusion}

Authors, illustrators and publishing houses must consider that people are diverse. Reading challenges should not be viewed as a "disability issue", but rather as contextual, situational and experienced by most people. Consequently, many types of people can benefit from reading the same types of books. Adapted books that are universally designed look like any other mainstream book. The books should be perceived as both relevant and appealing to a variety of readers, although the motivations for selecting the books might differ. For instance, a person with reading disabilities might select a book that is perceived as easier to read due to reading challenges. In contrast, a patient in a hospital may select the same book due to fatigue or decreased concentration due to illness or consumption of strong medicines. People learning a new language may prefer the books due to easier language. Despite the differences in motivation, the actual need is the same, simply to enjoy a good book. Consequently, user diversity is the norm rather than exception regarding reading and must be considered in the production and promotion of adapted books. There are, however, potentially different needs for adaptation in the various user groups. Practitioners involved in developing adapted books must therefore have extensive knowledge of the implications of the various reading challenges. By incorporating knowledge of this user diversity into the production of books, without losing the universal need for high quality books off sight, there is a higher chance that the books will appeal to a broad variety of users.

\section{References}

[1] M. Becker, N. McElvany, and M. Kortenbruck, Intrinsic and extrinsic reading motivation as predictors of reading literacy: A longitudinal study, Journal of Educational Psychology, 102 (2010), 773-785.

[2] L.B. Gambrell, Seven rules of engagement: What's most important to know about motivation to read, The Reading Teacher, 65 (2011),172-178.

[3] P.M. Bal, and M. Veltkamp, How does fiction reading influence empathy? An experimental investigation on the role of emotional transportation, PLOS ONE, 8 (2013), 1-12.

[4] C.S. Ross, Making choices, The Acquisitions Librarian, 13 (2000), 5-21.

[5] S.P. McGeown, L.G. Duncan, Y.M. Griffiths, and S.E. Stothard, Exploring the relationship between adolescent's reading skills, reading motivation and reading habits, Reading and Writing, 28 (2015), 545569.

[6] V. Howard, The importance of pleasure reading in the lives of young teens: Self-identification, selfconstruction and self-awareness. Journal of Librarianship and Information Science, 43 (2011), 46-55.

[7] S.D. Krashen, The power of reading: Insights from the research. 2nd ed., Libraries Unlimited, Westport, Conneticut, 2004.

[8] M.K. Swartz, and C.G. Hendricks, Factors that influence the book selection process of students with special needs, Journal of Adolescent \& Adult Literacy, 43 (2000), 608-618.

[9] G. Berget, and S. Fagernes, "I'm not stupid" - Attitudes towards adaptation among people with dyslexia, Human-Computer Interaction. Theories, Methods, and Human Issues, (2018), 237-247. Springer, Cham.

[10] L. O'English, J.G. Matthews, and E.B. Lindsay, Graphic novels in academic libraries: From Maus to manga and beyond, The Journal of Academic Librarianship, 32 (2006), 173-182.

[11] A. Müller, Introduction: Adapting canonical texts in children's literature, In: A. Müller (ed.), Adapting canonical texts in children's literature (p.1-8), Bloomsbury, London, 2013. 
[12] J. Roe, et al., Teaching literacy through Braille in mainstream settings whilst promoting inclusion: Reflections on our practice, International Journal of Disability, Development and Education, 61 (2014), 165-177.

[13] S. Véliz, et al., Towards a participative approach for adapting multimodal digital books for deaf and hard of hearing people, International Journal of Child-Computer Interaction, 11 (2017), 90-98.

[14] G. Berget, The use and promotion of adapted books in Norwegian public libraries, Journal of Librarianship and Information Science, 2021.

[15] E.W. Brante, 'I don't know what it is to be able to read': How students with dyslexia experience their reading impairment, Support for Learning, 28 (2013), 79-86.

[16] M.J. Snowling, et al., Dyslexia and Developmental Language Disorder: Comorbid disorders with distinct effects on reading comprehension, Journal of Child Psychology and Psychiatry, 61 (2020), 672-680.

[17] E. van Wingerden, et al., Foundations of reading comprehension in children with intellectual disabilities, Research in Developmental Disabilities, 60 (2017), 211-222.

[18] A.R. Lederberg, B. Schick, and P.E. Spencer, Language and literacy development of deaf and hard-ofhearing children: Successes and challenges, Developmental Psychology, 49 (2013), 15-30.

[19] S.H. Moghadam, Z. Zainal, and M. Ghaderpour, A review on the important role of vocabulary knowledge in reading comprehension performance, Procedia - Social and Behavioral Sciences, 66 (2012), 555-563.

[20] W. Clausen, et al., Health literacy among people with serious mental illness, Community Mental Health Journal, 52 (2016), 399-405.

[21] L.K. Palmer, The relationship between stress, fatigue, and cognitive functioning, College Student Journal, 47 (2013), 312-325.

[22] S. Iwarsson, and A. Ståhl, Accessibility, usability and universal design: Positioning and definition of concepts describing person-environment relationships, Disability and Rehabilitation, 25 (2003), 57-66.

[23] M.F. Story, Maximizing usability: The principles of universal design, Assistive Technology, 10 (1998), 4-12.

[24] Center for Universal Design, About UD, 2008, Available from: https:/www.ncsu.edu/ncsu/design/ cud/about_ud/about_ud.htm.

[25] E. Steinfe-dd, and J.L. Maisel, Universal design: Creating inclusive environments. Wiley, New Jersey, 2012.

[26] Design for All Europe, What is DfA, 2004, Available from: http://dfaeurope.eu/what-is-dfa/.

[27] Design for All Foundation, Design for All is design tailored to human diversity, n.d., Available from: http://designforall.org/design.php.

[28] Books for Everyone, English, 2019, Available from: https://lesersokerbok.no/english/.

[29] M. Rinck, and M. Van der Linden, Kjenner du kjempen? [Do you know the Giant?]. Fortellerforlaget, Oslo, 2009.

[30] H. Kramer, Minner i bilder [Memories in pictures]. Aldring og Helse, Tønsberg, 2014.

[31] B.-E. Westergård, and T. Heia, Venner: En bok for mennesker med utviklingshemming og deres hjelpere [Friends: A book for people with developmental impairments and their helpers], Universitetsforlaget, Oslo, 2014.

[32] K. Hagerup, and L. Aisato, Jenta som ville redde bøkene [The girl who wanted to save the books], Gyldendal, Oslo, 2017.

[33] A. Papola-Ellis, Text complexity: The importance of building the right staircase, Reading Horizons, 53 (2014), 1-27.

[34] J.E. McCarthy, and S.J. Swierenga, What we know about dyslexia and Web accessibility: A research review, Universal Access in the Information Society, 9 (2010), 147-152.

[35] K. Hamsun, and M. Erntsen, Sult [Hunger], Minuskel, Oslo, 2019.

[36] J.E. Andersen, Den nye Julie [The new Julie], Orkana, Stamsund, 2012.

[37] M. Breen, and J. Jordahl, Women in battle: Freedom, equality, sisterhood. Hot Key, London: 2018. 